\section{Taking a precautionary approach to nanotechnology}

\section{Dónal P. O’Mathúna}

School of Nursing \& Human Sciences; Biomedical Diagnostics Institute; Institute of Ethics Dublin City University, Dublin, Ireland

\begin{abstract}
Nanotechnology is developing at a rapid pace. Concerns have been raised about the risks nanotechnology may carry for human health and the environment. The precautionary principle has developed within environmental ethics as a way to reduce the risk of harm with emerging technologies. It has been incorporated into a number of documents addressing nanotechnology risks, including the European Commission's Code of Conduct for Responsible Nanosciences and Nanotechnologies Research. The central features of the precautionary principle are reviewed here. These include addressing situations of scientific uncertainty and serious or irreversible harm, developing a proportionate response, and having reasonable grounds for concern. These factors will be applied to carbon nanotubes to demonstrate how the precautionary principle can lead to practical guidelines during the development of nanotechnology.
\end{abstract}

\section{Introduction}

Industrial development sometimes collides headlong with the environment. Each year, more environmental disasters are added to the list of nasty surprises that can accompany technological developments. Such surprises cause serious damage to environmental and human health, catch scientists and the public off-guard, and are linked to deeply entrenched approaches to technology. ${ }^{1}$ Examples abound, with current focus on the March 2011 earthquake and tsunami in Japan that led to serious problems at the Fukushima Daiichi nuclear power plant. In October 2010, attention focused on Hungary where red sludge escaped from an aluminum processing plant and caused widespread damage. Earlier in 2010, the largest marine oil spill occurred in the Gulf of Mexico and took three months to get under control because of difficulties plugging the deepwater source of oil.

Such disasters bring into focus the environmental risks associated with scientific research and industrial development. At the same time, technology and scientific ingenuity play an important role in responding to disasters. This was seen also in 2010 when 33 Chilean miners were trapped nearly half a mile underground. Technology played a major role in sustaining and eventually rescuing the miners from their confinement.

Nanotechnology promises, among many other things, to provide new tools to assist in environmental clean-ups. ${ }^{2}$ However, because nano-enabled products are at such an early stage of development, much remains unknown about their potential benefits, and whether they might bring some nasty surprises.

All technologies carry some risks, but the scale of the damage has been increasing. Nuclear technology has come under serious scrutiny again because of its potential for destruction as highlighted by the Japanese earthquake. Other damage accumulates more slowly, but can be just as destructive. The cost of cleaning up nasty surprises is also becoming unsustainably high. Even when the damage is contained and the clean-up under way, the pain and suffering of those most directly impacted must be addressed. Long-term health, safety and environmental consequences must be assessed. Social and psychological recovery can take a long time. Physical damage likewise can be far-reaching, extending even to future generations.

But as the sludge recedes and the smells dissipate, deeper questions arise. Challenging issues must be faced by researchers and producers of such products. What can nanotechologists learn from these surprises? What lessons have not been learned from previous environmental disasters? And what sorts of things can be done differently to avoid similar problems with nanotechnology?

\section{Introducing nanotechnology}

Nanotechnology is developing in the midst of such thinking. Past problems and disasters have led to greater emphasis on the social, ethical, legal and environmental implications of nanotechnology. ${ }^{3}$ The risks of nanotechnology are basically unknown or uncertain because nanotechnology is so new. This calls for a different approach to evaluating risk compared to traditional risk-benefit assessment. Lacking the necessary scientific data for such assessments, evaluation of the potential risks and benefits must proceed on the basis of the strengths and weaknesses of the arguments offered. ${ }^{4}$ Which claims are best supported? Which arguments are logically coherent? Assessment of such arguments is part of what ethical analysis provides.

The precautionary principle is one of several ethical principles proposed to assist in risk assessment. ${ }^{5}$ The approach can be rooted in other ethical principles such as that of nonmaleficence, or avoiding harm. For example,
Correspondence: Dónal P. 0’Mathúna, School of Nursing \& Human Sciences, Dublin City University, Glasnevin, Dublin 9, Ireland. Tel. +353.1.700.7808 - Fax: +353.1.700.5688.

E-mail: donal.omathuna@dcu.ie

Key words: precautionary principle, risk, nanoethics.

Received for publication: 16 June 2011. Accepted for publication: 26 October 2011.

This work is licensed under a Creative Commons Attribution NonCommercial 3.0 License (CC BYNC 3.0).

(C)Copyright D.P. O'Mathúna, 2011

Licensee PAGEPress, Italy

Nanotechnology Development 2011; 1:e6

doi:10.4081/nd.2011.e6

developers and producers of pharmaceuticals have an ethical obligation to show that new drugs do not cause serious or extensive harm to patients. The precautionary principle would apply this ethical idea more broadly in claiming that nanotechnologists have an ethical responsibility towards humans and the environment that requires them to demonstrate the safety of their products and devices before releasing them. The idea of moral duties and responsibilities ties into a deontological approach to ethics, which can be used to justify the precautionary principle. The focus here will not be on providing an extensive justification for the precautionary principle. This has been done elsewhere, although much further work is needed to clearly articulate the ethical justification for specific aspects of the precautionary principle. ${ }^{6,7}$ This article will focus on how the precautionary principle can contribute to an ethically sound approach to nanotechnology development.

\section{The precautionary principle}

Environmental nasty surprises have played an important role in the development of the precautionary principle. Past surprises feature prominently in calls for the adoption of a more precautionary approach. A study commissioned by the European Environment Agency demonstrated how the precautionary principle could have reduced or prevented much harm if it had been implemented during several historical examples. ${ }^{3}$

The precautionary principle was first articulated in the $1970 \mathrm{~s}$ in clean air legislation responding to deforestation problems. ${ }^{6}$ German legislation used the precautionary principle to justify introducing air quality regulations even though uncertainty remained regarding the strength of the evidence that airborne pollutants caused the damage. 
The principle was subsequently included in the United Nations' 1992 Rio Declaration on Environment and Development. Developed at the so-called Earth Summit, it stated:

In order to protect the environment, the precautionary approach shall be widely applied to States according to their capabilities. Where there are threats of serious or irreversible damage, lack of full scientific certainty shall not be used as a reason for postponing cost-effective measures to prevent environmental degradation. ${ }^{8}$

Many international organizations have since incorporated the precautionary principle into declarations and treaties. ${ }^{6}$ The precautionary principle underpins the regulatory system for chemicals in the European Union (EU), called the Registration, Evaluation, Authorisation and Restriction of Chemicals (REACH). ${ }^{9}$ Although its provisions do not specifically refer to nanomaterials, they are covered by REACH. ${ }^{10}$ In 2008, the European Commission adopted a voluntary code of conduct for research in nanosciences and nanotechnologies (N\&N). This Code of Conduct explicitly includes the precautionary principle as foundational to good practice.

$N \& N$ research activities should be conducted in accordance with the precautionary principle, anticipating potential environmental, health and safety impacts of $N \& N$ outcomes and taking due precautions, proportional to the level of protection, while encouraging progress for the benefit of society and the environment. ${ }^{11}$

\section{General guidelines}

The precautionary principle has been formulated in various ways, which is taken by some to be a significant weakness. ${ }^{5}$ However, rather than prescribing a specific approach in every situation, the precautionary principle can be viewed as a set of guidelines to be used in assessing precautionary steps that may reduce potential harms as new technologies are being developed. A list of the guidelines commonly found in different formulations of the precautionary principle is given in Table $1 .^{12}$ Every formulation does not include each guideline.

Underlying the different formulations of the precautionary principle are approaches that can be categorized as stronger or weaker versions, or what have also been called strict and active forms. ${ }^{13}$ Many of the guidelines allow for a range of interpretations. A stricter version of the precautionary principle is exemplified by the 1987 London Declaration on the Protection of the North Sea. This called for regulation of substances which could damage or harm living resources in the sea even where there is no scientific evidence to prove a causal link between emissions and effects. ${ }^{14}$ An active approach to the precautionary principle is seen in how the EU describes the type of evidence needed to trigger precaution. It states that the precautionary principle applies when there are indications through preliminary objective scientific evaluation that there are reasonable grounds for concern about the adequacy of current protective strategies to prevent harm. ${ }^{15}$

Stricter versions of the precautionary principle propose more restrictive responses to potential harms. For example, the ETC group, an environmental advocacy group, typically adopts a strict version of the precautionary principle in calling for global moratoria on activities it deems highly risky. Such activities include the use of synthetic nanoparticles in laboratories or new commercial products, and the development of molecular self-assembly within nanotechnology. ${ }^{16}$ Active approaches sometimes call for moratoria, but also permit development once it is accompanied by various types of monitoring, testing, and regulation.

Critics of the precautionary principle often attack only the stricter versions. In some cases, extremely strict versions are erected as straw men to allow easy dismissal. For example, Harris and Holm claim that the precautionary principle would lead to bans on pregnancy and apple pie because these carry some risks. ${ }^{17}$ Such claims are caricatures of the precautionary principle and do not reflect the common sense dimension of active versions that seek a more balanced approach. ${ }^{18}$

An active formulation of the precautionary principle is advocated here, where all the relevant factors are balanced against one another, and against other important values such as social justice and the importance of developing new therapies. A helpful definition that seeks to address the limitations of other formulations has been proposed by UNESCO. When

\section{Table 1. Guidelines found in various formulations of the precautionary principle.}

\section{General guidelines}

i. Scientific uncertainty and lack of information should trigger a precautionary approach and not be taken as sufficient reasons to postpone appropriate precautionary measures.

ii. Preventative strategies should be developed to avoid serious or irreversible harm to the environment and health.

iii. Precautionary strategies should be proportionate and appropriate in light of what is known about potential harms and benefits.

iv. Precaution should be based on scientific evidence and analysis that there are reasonable grounds for concern.

v. The burden of proof should be shifted to those seeking to develop or market products or processes with significant risks.

vi. The polluter pays principle should apply when damages occur.

vii. Alternative means of achieving the same outcomes but with reduced risk of harm should be identified.

viii. Further scientific research should be conducted and systematically reviewed to reduce uncertainty and provide additional evidence for risk assessment.

ix. All stake-holders, including the public, should be involved in the decision-making process regarding technological risks.

human activities may lead to morally unacceptable harm that is scientifically plausible but en to avoid or on the terms in this definiences not and are included other important values. ${ }^{19}$ While some

\section{Applying the precautionary}

Table 1 gives a comprehension list of guidenes included within the precautionary princimost commonly encountered guidelines will be discussed in more detail now and

\section{The precautionary principle} alternative products and strategies.

Synthetic nanoparticles have already been . 
produced, and much remains unknown about their risks. Admittedly, causal links to serious damage have not been clearly established, but there are good scientific reasons to restrict or delay the release of at least some nanoparticles. Carbon nanotubes provide a specific case in point. These account for 80 percent of the nanomanufacturing sector, with 500 tons produced globally in 2008, and millions of tons expected to be produced annually in the near future. ${ }^{20}$ Workers and researchers are already being exposed to these nanoparticles. Yet, a 2009 toxicity review could find no data on human exposure to carbon nanotubes. ${ }^{20}$ A 2010 review located eight occupational exposure studies, primarily published in the previous two years. ${ }^{21}$

The precautionary principle would apply here even though uncertainty remains about the link between carbon nanotubes and any human or environmental harm. In quantitative risk analysis, only toxicity data for the specific product are relevant. Traditional risk assessment is further hampered for carbon nanotubes by a lack of knowledge about the use, exposure, and risk management measures already in place for carbon nanotubes. ${ }^{21}$ Challenges arise even in preparing carbon nanotubes for toxicity studies, and in drawing implications for human health from animal studies. ${ }^{22}$

Based on a traditional risk assessment, reviewers concluded that the carbon toxicity data publicly available up to June 2010 contains substantial uncertainties in terms of exposure and hazard and therefore these results should not be used for any regulatory decisionmaking. ${ }^{21}$ Within a precautionary principle approach, the very uncertainties themselves would be taken into account in decision-making. These reviewers take this approach, and recommend various types of studies to help fill the current gaps. In addition, they recommend new testing paradigms to evaluate and assess the toxicity of nanoparticles, especially those likely to be inhaled. They also note that the risk assessment methodology as currently used for the evaluation of chemicals might need adaption to account for the specific properties of nanoparticles. $^{21}$

\section{Serious or irreversible harm}

Most types of nanoparticles have insufficient data to establish whether their toxic effects are serious or irreversible. Their small size and large surface area to volume ratio make them attractive as drug delivery systems, but also raise serious concerns about toxicity. According to prominent nanotoxicity researchers, An emerging 'rule of thumb' suggests that nanoparticles less than $100 \mathrm{~nm}$ in diameter can enter cells, those with diameters below $40 \mathrm{~nm}$ can enter the cell nucleus and those that are smaller than $35 \mathrm{~nm}$ can pass through the blood-brain barrier and enter the brain. ${ }^{23}$ Particles that can enter the nucleus or pass through the blood-brain barrier carry a high potential for damaging effects, even if potentially beneficial effects can also be envisioned.

The 2009 review of carbon nanotubes toxicity found 21 animal and tissue studies, most of which showed statistically significant damage in the samples exposed to nanoparticles compared to the control groups. ${ }^{20}$ While there are limitations to the application of these experimental studies to real-life exposures in humans, the reviewers concluded that if carbon nanotubes get into the body, they will cause damage. In addition, carbon nanotubes and other fullerenes are composed primarily of carbon. This makes them highly hydrophobic and likely to accumulate in tissues and the environment. Their effects and toxicity are therefore likely to be long-lasting and persistent, with damage not being apparent until some time has passed. ${ }^{22}$ These preliminary findings suggest that the precautionary principle should apply to carbon nanotubes.

A range of engineered nanoparticles is also being developed for biomedical applications. Such metallic nanoparticles include gold colloids, iron oxide nanoparticles, quantum dots and others. The metals contained include cadmium, selenium, cobalt and nickel. A review of in vivo animal studies found that gold nanoparticles accumulate in various animals, primarily in the liver and spleen. ${ }^{24}$ Those smaller than $12.5 \mathrm{~nm}$ crossed the blood-brain barrier and accumulated in the brain. At the same time, little or no toxic effects were found in many studies. However, gold nanoparticles of specific sizes did cause toxicity in some studies when given orally or by intraperitoneal injection.

Many metallic nanoparticles were found to persist in biological systems, raising concerns about accumulation after repeated dosing. Much remains unknown about the biological distribution and health effects of quantum dots. Those made from cadmium and selenium raise additional questions due to the known toxicities of the metals themselves. These can be released during digestion or over time. In spite of the potential beneficial applications of metallic nanoparticles, preliminary studies point to their potential toxicity and high persistency. The precautionary principle would insist on detailed toxicological studies before considering their biomedical applications. ${ }^{24}$

\section{Proportionate response}

Another guideline within the European Commission's Code of Conduct, and other active forms of the precautionary principle, is that responses to available data should be proportionate to the level of anticipated harm. ${ }^{11}$ The precautionary principle is not simply about banning products or issuing moratoria. Thus, for example, recommendations have been made by many organizations to fund and conduct many more nanotoxicology studies than have been carried out to date. ${ }^{24}$ Encouraging this type of research is in keeping with the precautionary principle.

Given what is known about the toxicity of carbon nanotubes, engineering controls to limit workers' exposure have been recommended along with the use of rigorous personnel protective equipment. ${ }^{20}$ Such responses address inhalation exposure, and current data suggest that oral and dermal exposure many require different responses..$^{21}$ Another implication of a proportional approach is that as scientific evidence increases, and more becomes known about actual risks and harms, the precautionary responses should change. This may lead to increased or decreased levels of protection depending on study results. This will require complex and challenging regulatory arrangements which will need to be reviewed on a regular and case-by-case basis. However, this is preferable to a simplistic all or nothing response which does not reflect the difficult decisions that must be made in the early stages of developing new technologies and products. This is the point at which biomedical applications of nanotechnology are now positioned.

\section{Reasonable grounds for concern}

The precautionary principle should not be invoked just because any harm can be envisioned. Speculative ethics has a tendency to argue about the ethics of new technologies based on what if arguments. ${ }^{25}$ Such approaches lead to projections about the future where some anticipated harm is envisioned and used to justify halting development. On the other hand, potential benefits can likewise be proposed and used to justify proceeding. Such arguments provide little help with the decisions needed about technology.

The precautionary principle as developed in its active form calls for reasonable scientific evidence connecting a substance or process with the potential harm. The European Commission's discussion of the precautionary principle states that this should be preliminary objective scientific evaluation that provides reasonable grounds for concern. ${ }^{15}$

While such scientific data will be incomplete and retain uncertainty, other forms of reasonable arguments can be introduced. For example, while direct toxicity data is limited for carbon nanotubes, analogies can be drawn to other, similar chemicals. Thus, comparisons have been made between the shapes and properties of carbon nanotubes and asbestos, and have led to concerns that carbon nanotubes might have analogous adverse effects. These connections have been reinforced by animal 
toxicity studies showing that carbon nanotubes can cause mesothelioma, a rare cancer previously associated with asbestos. ${ }^{22}$ Not only is this a serious harm given the poor prognosis with mesothelioma, but it is especially sinister as symptoms may not develop until 30 to 40 years after persistent exposure. ${ }^{3}$ Much remains unknown about how any of these fibers might cause mesothelioma, but the preliminary data are sufficient to show that precautionary strategies are scientifically warranted with carbon nanotubes.

\section{Balancing progress with precaution}

Some critics of the precautionary principle claim that it is anti-scientific and antiprogress. Harris and Holm claim that it inexorably requires science to be ultra-conservative and irrationally cautious and societies to reject a wide spectrum of possible benefits from scientific advance and technological change. ${ }^{17}$ This article has sought to show that this is not the case for the precautionary principle in general, and certainly not for its active formulation. As just one example, the European Commissions' Code of Conduct for nanotechnologists calls for application of the precautionary principle while encouraging progress for the benefit of society and the environment. ${ }^{11}$ The precautionary principle is one of several ethical principles that must be balanced against one other as science and technology make their contribution to society. This involves taking the price of precaution into account. Every precautionary strategy will have a cost, either in resources, allowing current harms to continue or delaying potential benefits. For example, the introduction of nanovaccines into fish farming should address uncertainty about risks, but a precautionary approach should include evaluating the detrimental effects of current farming practices that could be removed by nanovaccines, the so-called risks of non-action. ${ }^{19}$ Examination of all such factors are integral to balancing precaution and progress, yet formulations of the precautionary principle are silent on the cost of precaution. ${ }^{7}$ On the other hand, critics of the precautionary principle focus on the price of precaution, sometimes alleging that these costs reflect a bias against science and technology.

Rather than being anti-scientific, the precautionary principle is pro-scientific and calls for more science. The research proposed may have a different focus, particularly in studying the health and environmental risks of new developments, like nanoparticles. Underlying its approach is a set of values and attitudes that may clash with other values that can arise within research and development. Precaution urges recognition of the inherent vulnerability of the environment and human bodies. In light of that, precaution gives priority to protecting these vulnerable systems and requires gratitude, empathy, restraint, humility, respect and compassion. ${ }^{26}$

Such values can collide with the drive to market, and the need to get return from investments. As science and technology push forward, there is always a danger of pushing too far too quickly. Throughout history, the humanities have warned technologists and society of such dangers. From Icarus to Frankenstein, from Brave New World to GAT$T A C A$, literature reminds us of the temptation to fly past our limits, or to throw caution to the wind. ${ }^{12}$ Michael Crichton has added Prey to this list so that nanotechnology also has its fictional reminder of the vale of the precautionary principle. ${ }^{27}$ Such narratives are important reminders of human nature, the dangers of technological hubris, and the need for humility and precaution.

\section{Conclusions}

Back in the non-fiction world, critics of the precautionary principle note that it provides little concrete guidance for researchers in the lab or industries developing products containing nanoparticles. The principle itself does not provide a straight-forward recipe for all situations. However, its various formulations, including the UNESCO statement, point to the importance of stakeholder engagement. ${ }^{6}$ Given that many aspects of a precautionary approach involve value-based concepts, a plurality of views should be encouraged in discussing new developments. This is challenging given the lack of knowledge and interest found when such activities were conducted. ${ }^{19}$ At the same time, different perspectives can serve to highlight where caution has been overlooked.

The precautionary principle is similar to other ethical principles. These are general statements about the importance of taking certain values seriously. They are not formulas or legal codes that provide specific answers for every eventuality. Concepts like justice and peace are difficult to pin down and develop consensus around, but this does not make them irrational or irrelevant. ${ }^{18}$ Just as medical researchers have a responsibility to protect participants in their studies, nanotechnology researchers and developers have a responsibility to protect those who will be exposed to their processes and products. Applying the precautionary principle is one way to operationalise such responsibilities and help clarify the various options available, not produce simplistic solutions. The precautionary principle points towards specific steps in individual situations that can help to balance precaution and progress. Taking due precaution is a responsible way to reduce the risk that some day nanotechnology will be found to have caused yet another nasty surprise.

\section{References}

1. Howard J. Environmental "nasty surprise" as a window on precautionary thinking. IEEE Technol Soc 2003;21:19-22.

2. Aglietto I, Carboni D. RECAM ${ }^{\circledR}$ : a new innovative nanostructure material can solve the environmental crisis in the Gulf of Mexico. ENT Magazine 2010;1:57-66.

3. Harremoës P, Gee D, MacGarvin M, Stirling A, Keys J, Wynne B, Vaz SG, editors. Late lessons from early warnings: the precautionary principle 1896-2000. Copenhagen: European Environment Agency; 2001. Available from: http://www. genok.org/filarkiv/File/late_response.pdf

4. Hansson SO. Great uncertainty about small things. Techné 2004;8:26-35.

5. John SD. How to take deontological concerns seriously in risk-cost-benefit analysis: a re-interpretation of the precautionary principle. J Med Ethics 2007;33:221-4.

6. World Commission on the Ethics of Scientific Knowledge and Technology (COMEST). The precautionary principle. Paris: UNESC0; 2005. Available from: http://unesdoc.unesco.org/images/0013/00 1395/139578e.pdf

7. Munthe $\mathrm{C}$. The price of precaution and the ethics of risk. Berlin: Springer; 2011.

8. United Nations. Rio declaration on environment and development; 1992. Available from: http://www.unep.org/Documents. Multilingual/Default.asp?documentid=78 \&articleid $=1163$

9. European Group on Ethics in Science and New Technologies to the European Commission. Opinion on the ethical aspects in nanomedicine; 2007. Available from: http://ec.europa.eu/bepa/europeangroup-ethics/docs/publications/opinion_21_nano_en.pdf

10. European Commission. Nanomaterials in REACH; 2008. Available from: http://ec. europa.eu/environment/chemicals/reach/ $\mathrm{pdf} /$ nanomaterials.pdf

11. European Commission. Code of conduct for responsible nanosciences and nanotechnologies research; 2009. Available from: http://ec.europa.eu/research/science-society/document_library/pdf_06/ nanocode-apr09_en.pdf

12. O'Mathúna DP. Nanoethics: big ethical issues with small technology. London: Continuum Press; 2009.

13. Phoenix C, Treder J. Applying the precau- 
tionary principle to nanotechnology. Center for Responsible Nanotechnology; 2004. Available from: http://crnano.org/precautionary.htm

14. Second International Conference on the Protection of the North Sea. London; 1987. Available from: http://www.seas-at-risk. org/1mages/1987\%20London\%20Declarati on.pdf

15. European Commission. Communication from the Commission on the precautionary principle; 2000. Available from: http://ec.europa.eu/dgs/health_consumer/l ibrary/pub/pub07_en.pdf

16. ETC group. Available from: http://www.etcgroup.org

17. Harris J, Holm S. Extending human lifespan and the precautionary paradox. J Med Philos 2002;27:355-68.

18. Attfield R. Environmental ethics: an overview for the Twenty-First Century. Cambridge: Polity Press; 2003.
19. Myhr AI, Myskja BK. Precaution or integrated responsibility approach to nanovaccines in fish farming? A critical appraisal of the UNESCO precautionary principle. Nanoethics 2011;5:73-86.

20. Genaidy A, Tolaymat T, Sequeira R, et al. Health effects of exposure to carbon nanofibers: systematic review, critical appraisal, meta analysis and research to practice perspectives. Sci Total Environ 2009;407:3686-701.

21. Aschberger K, Johnston HJ, Stone V, Aitken RJ, Hankin SM, Peters SA, Tran CL, Christensen FM. Review of carbon nanotubes toxicity and exposure-appraisal of human health risk assessment based on open literature. Crit Rev Toxicol 2010;40:759-90.

22. Nagai H, Toyokuni S. Biopersistent fiberinduced inflammation and carcinogenesis: lessons learned from asbestos toward safety of fibrous nanomaterials. Arch Biochem
Biophys 2010;502:1-7.

23. Dawson KA, Salvati A, Lynch I. Nanoparticles reconstruct lipids. Nat Nanotechnol 2009;4:84-5.

24. Li Y-F, Chen C. Fate and toxicity of metallic and metal-containing nanoparticles for biomedical applications. Small 2011;7: 2965-80.

25. Nordmann A. If and then: a critique of speculative nanoethics. Nanoethics 2007;1:31-46.

26. Schettler T, Raffensperger C. Why is a precautionary approach needed? In: Martuzzi M, Tickner JA, editors. The precautionary principle: protecting public health, the environment and the future of our children. Copenhagen: World Health Organization; 2004. p. 63-83.

27. Crichton M. Prey. London: HarperCollins; 2002. 